\title{
A Narrative Review on Adverse Effects of Dasatinib With a Focus on Pharmacotherapy of Dasatinib-Induced Pulmonary Toxicities
}

\author{
Zahra Nekoukar ${ }^{1}$, Minoo Moghimi $^{1}$, and Ebrahim Salehifar ${ }^{2}$ \\ ${ }^{1}$ Mazandaran University of Medical Sciences Faculty of Pharmacy \\ ${ }^{2}$ Affiliation not available
}

March 22, 2021

\begin{abstract}
Chronic myeloid leukemia (CML), a myeloproliferative disorder, is caused by overactivity of BCR-ABL1 (breakpoint cluster region-Abelson) has been successfully treated by Tyrosine kinase inhibitors (TKIs). While imatinib is known as the firstline treatment of CML, in some cases other TKIs including dasatinib, nilotinib, bosutinib, and ponatinib may be preferred. Dasatinib, a second-generation TKI, inhibits multiple family kinases including BCR-ABL, SRC family kinases, receptor kinases, and TEC family kinases. It is effective against most imatinib-resistant cases except T315I mutation. Despite the superiority of dasatinib in CML hematologic and cytogenetic responses compared to imatinib, its potentially harmful pulmonary complications including pleural effusion (PE) and pulmonary arterial hypertension (PAH) may limit its use. Appropriate management of these serious adverse reactions is critical in both improving the quality of life and outcome of patients. In this narrative review, we will scrutinize the pulmonary complications of dasatinib and focus on the management of these toxicities.
\end{abstract}

\section{Hosted file}

Dasatinib Manuscript Final Version.pdf available at https://authorea.com/users/403272/ articles/514808-a-narrative-review-on-adverse-effects-of-dasatinib-with-a-focus-onpharmacotherapy-of-dasatinib-induced-pulmonary-toxicities

\section{Hosted file}

figure.pdf available at https://authorea.com/users/403272/articles/514808-a-narrativereview-on-adverse-effects-of-dasatinib-with-a-focus-on-pharmacotherapy-of-dasatinibinduced-pulmonary-toxicities 